\title{
Combating corrosion in geothermal wells
}

Geothermal energy holds
the potential to harvest vast
amounts of energy from within
the Earth's crust. So far, however,
exploitation of geothermal
energy can be limited by
corrosion - which damages
the metal pipes required to
carry high-temperature steam
generated deep underground.
In a new experiment, Andri
Thorhallsson and Sigrun
Karlsdottir at the University of
Iceland show how the problem
could be solved by building
these pipes with a particular
titanium alloy. Their results could
pave the way for a more rapid
expansion of geothermal energy
in the near future.

o far, humanity's efforts to expand

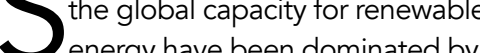
rapid developments of wind and solar power - but a promising alternative source can be found in the immense quantities of heat stored deep within Ectivity including lceland magh tectonic Earth's interior is pushed, mapwards transferring this heat far closer to the surface.

Over the past decades, geothermal energy has been utilised by discharging high-temperature geothermal fluid (steam, gasses, water, dissolved substances, and dispersed solids); the gaseous part of the geothermal steam is separated from the liquid part of the fluid and is run through spinning turbines, generating electricity without any need for fossil fuels. In Iceland, and various other active geothermal areas, geothermal wells are dilled and the geothermal fluid - steam, gases and liquiid - is discharged.
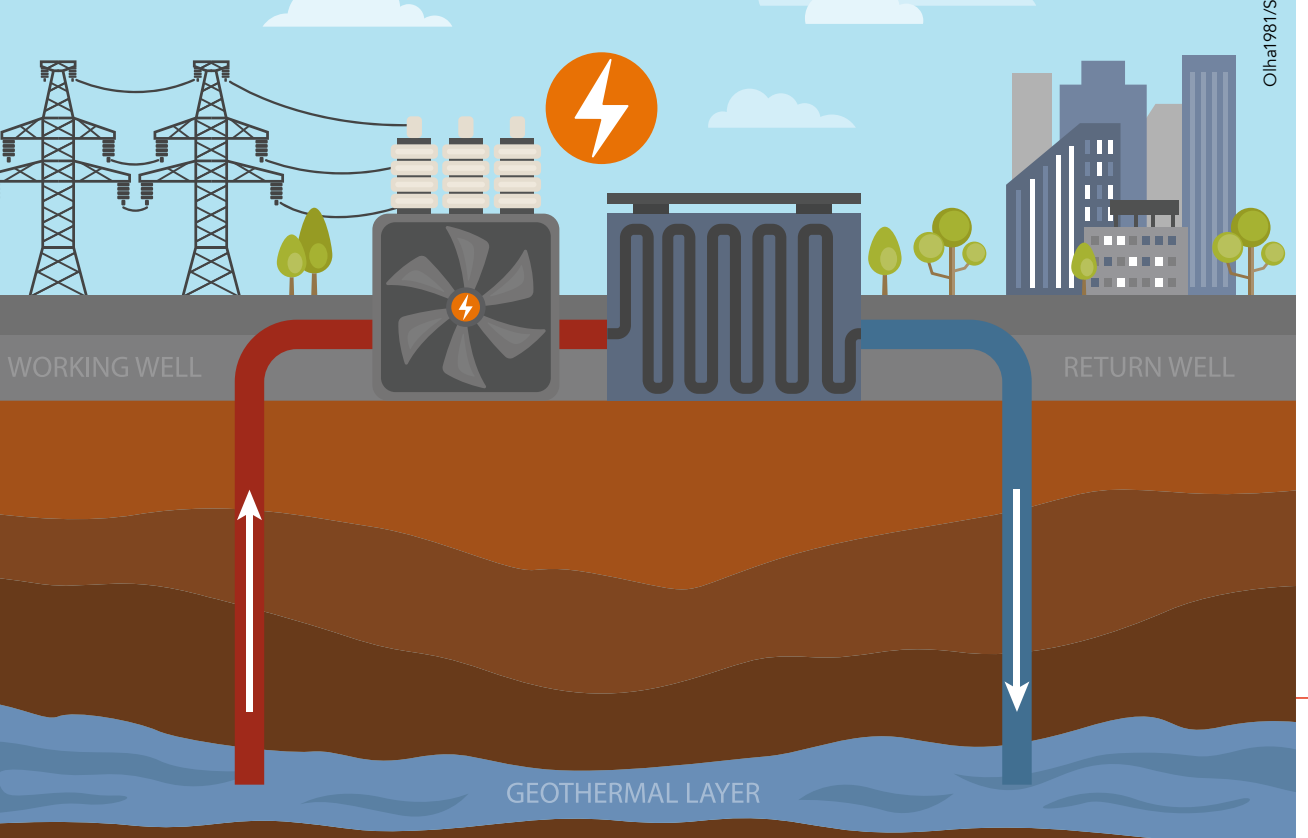

Named 'geothermal energy,' this technology holds the potential to supply a significant fraction of humanity's energy needs. Yet aside from a few small-scale operations, the heat contained in Earth's crust has so remained almost entirely untapped.

\section{THE THREAT OF CORRODING PIPES} According to Thorhallsson and Karlsdottir, particularly significant factor. The problem relates to the holes, or 'wells,' required. to convey the steam pressurised deep underground back to the surface. 'The drilled wells are cased with cylindrical pipes, which ensure the smooth discharge of geothermal fluid from the Earth's crust towards the surface', Thorhallsson explains. IIn order to achieve high energy efficiency, it is highly important that the piping material retains its integrity.

Currently, these pipes are often designed using carbon steel or low alloyed steel that have high strength but aluid discharged from. The geother wells contains several corrosive species: including hydrochloric acid $(\mathrm{HCl})$, hydrogen sulphide $\left(\mathrm{H}_{2} \mathrm{~S}\right)$, and carbon dioxide $\left(\mathrm{CO}_{2}\right)$.

As a result, the pipes become highly vulnerable to corrosion: a chemical reaction that converts metals into different compounds, including oxides, hydroxides, and sulphides. Altogether, the process not only roughens the inner surfaces of pipes, reducing the ability of the geothermal
fluid to travel smoothly along them; it also weakens their mechanical structures, or makes the piping porous at the part of the piping system that allows the mixing fluid This make the gothernal Hluid. This makes the geothermal wells

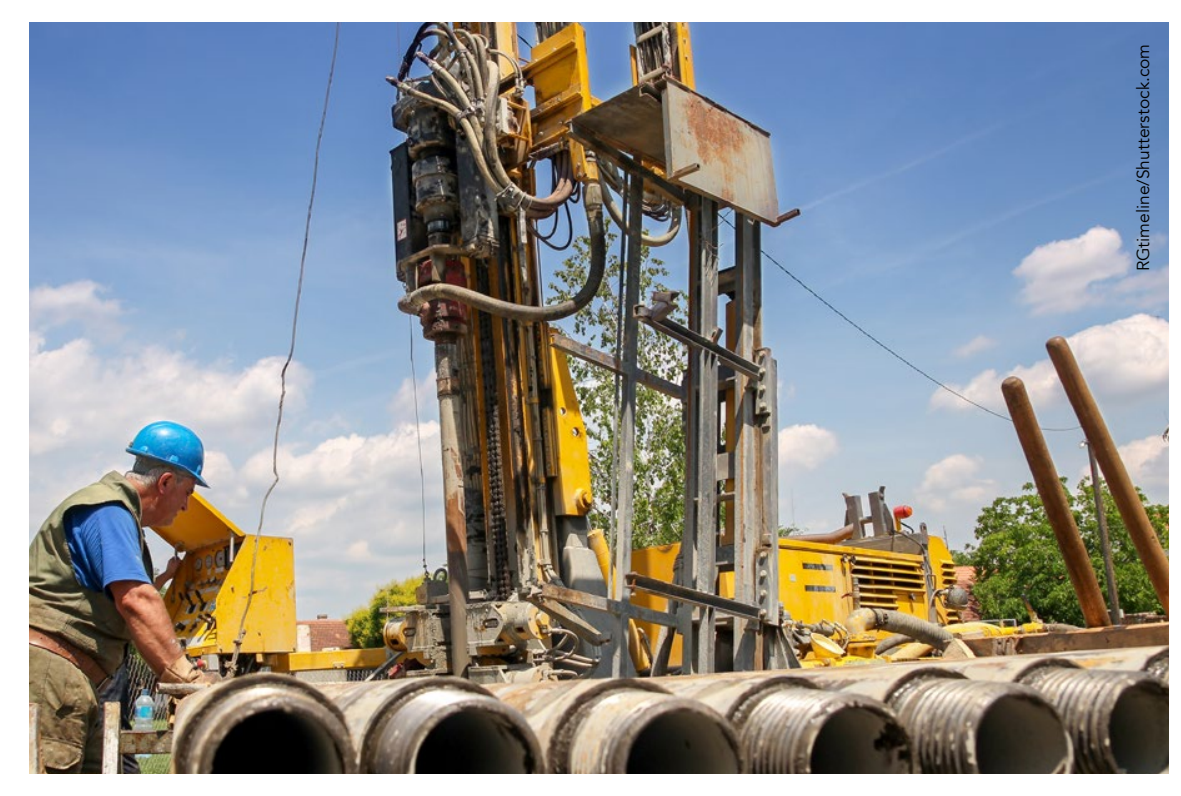

and high-energy fluid. In more severe cases, the piping system can collapse. As presul, the linethe or the geothers. A driving up the costs of geothermal energy. nickel, molybdenum, and zirconium. In

In their study, Thorhallsson and Karlsdottir aimed to address these based alloy, containing the elem-

higher temperatures. So far, however, its potential for use in geoth

TESTING CORROSION IN THE LAB Through their research, the duo explored this possibility for the first up in a lab, to simulate the whysical conditions that can be expected in actual high-temperature geotherma wells', Thorhallsson illustrates. 'This involved testing three different phase conditions of an artificial geothermal fluid in a testing volume containing three flow-through reactors.' Each of these reactors was cased with piping made from the material being tested on which corrosion could occur.

In their artificial set-up, the researchers tested two different water one mixed with $\mathrm{HCl}$ and the oth containing a mixture of $\mathrm{H}_{\mathrm{S}}$ and $\begin{array}{lll}\text { ENLISTING A } & \text { These advantages could provide greater } & \begin{array}{l}\mathrm{CO}_{2} \cdot \ln \text { the first } \\ \text { reactor, heated to } \\ \text { temperatures of }\end{array}\end{array}$ Recently, a lot of incentives for businesses and governments $350^{\circ} \mathrm{C}$, the samples research in the were boiled, geothermal industry in tectonically active regions to expand and completely has been dedicated evaporated to form to developing their rollout of geothermal energy. superheated steam, new piping

materials, which can better withstand previous studies, this particular metal the highly corrosive environment of Earth's crust. Promising advances in this area have been made using titanium, and titanium-based alloys. 'Titanium is a relatively expensive material, but can the corrosion is particularly ags where Thorhallsson describes.

These durable properties are due to the metals forming thin layers of titanium dioxide on their surfaces, which increases the corrosion resistance of the titanium significantly. Since titanium is far less reactive to corrosive gases, it can be immune to corrosion in geothermal piping system. Yet in addition to their costs, the mechanical structures of titanium-based materials can deteriorate at high temperatures - making them less sultable for the high temperatures experienced deep within Earth's crust. As a result, thorough analysis of the physica condition of the geothermal system must be conducted before design
construction of the piping system. has been shown to possess a crystal has been shown to possess a crystal
lattice structure with high mechanical stability, which it maintains even at

pressure exerted by the atmosphere on Earth's surface. As a result, this space contained a mixture of gaseous species
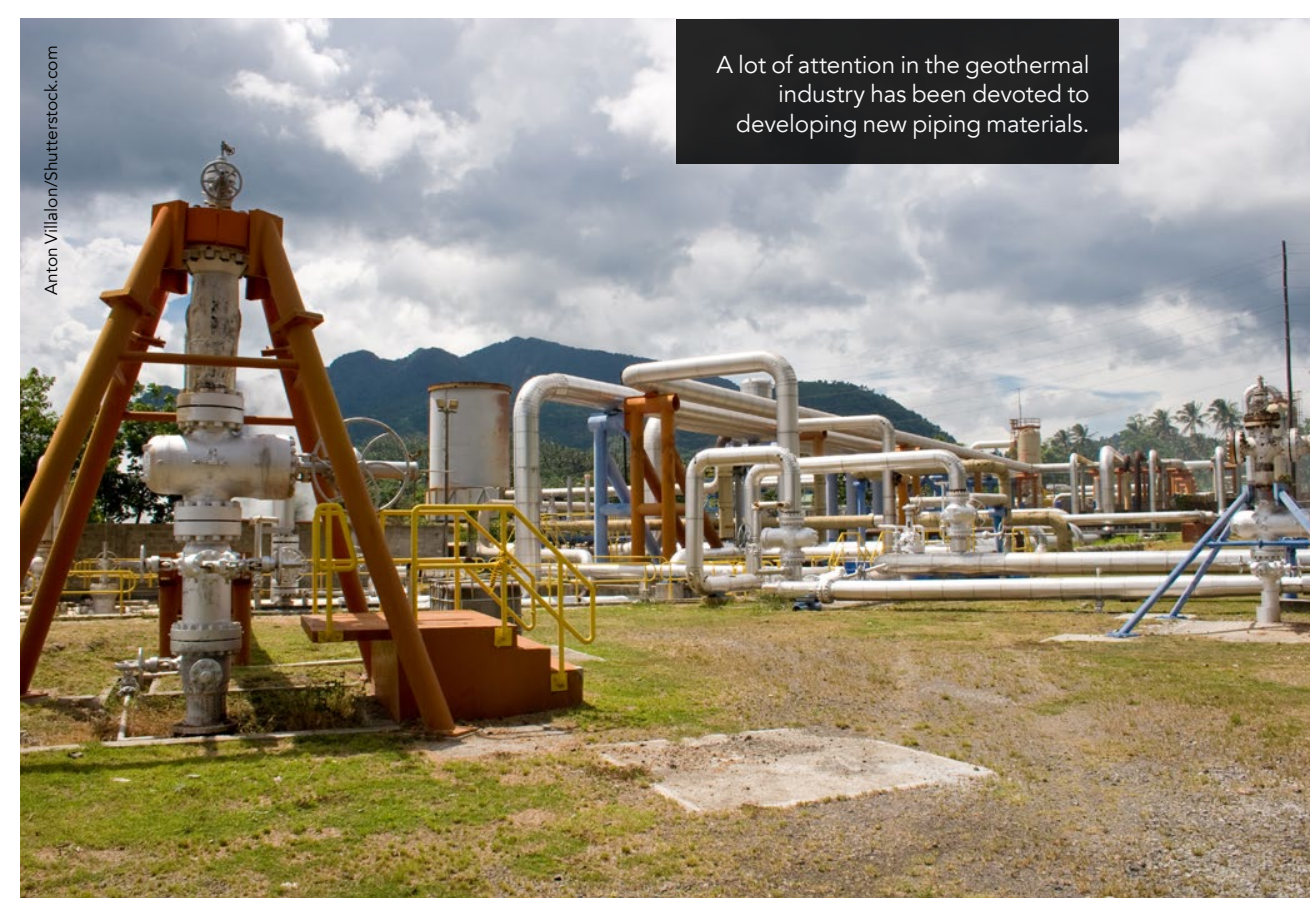


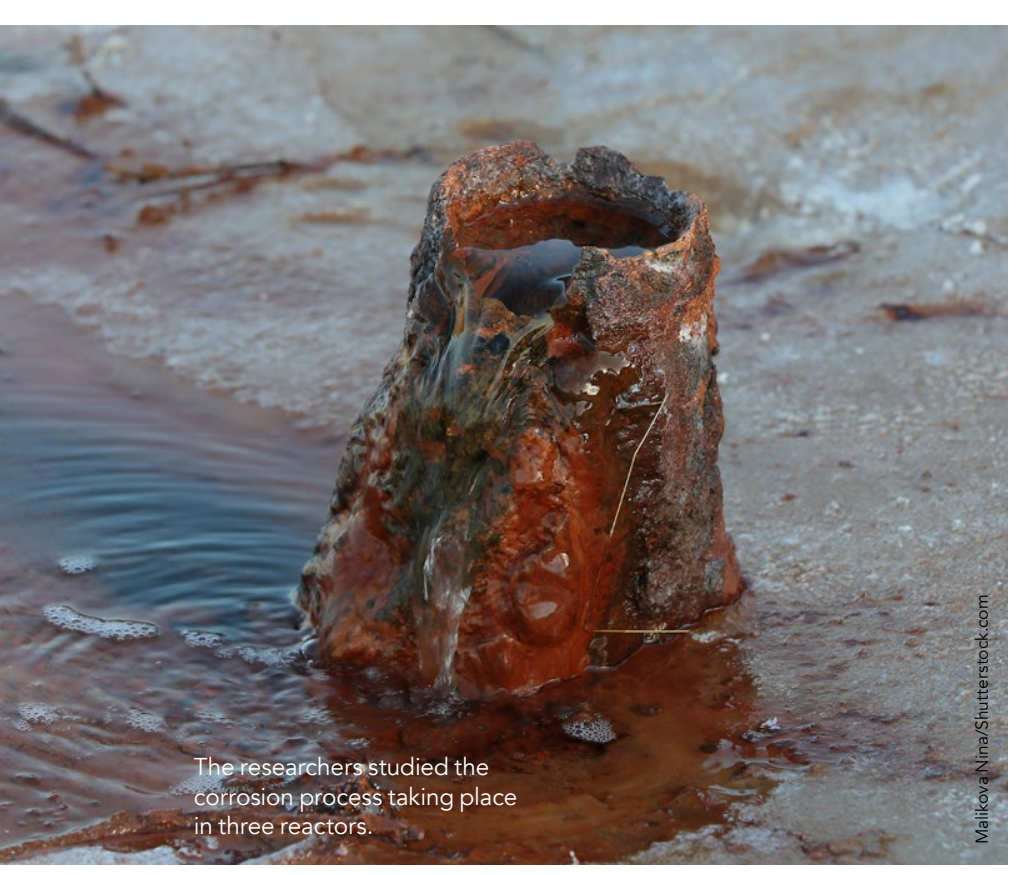

In the second reactor, heated to the same its reactor had a lower temperature of $180^{\circ} \mathrm{C}$ In these conditions, the steam began to condense; again forming a mixture of quid and gas.

\section{STUDYING CORRODED SAMPLES} To study the corrosion processes taking place in the three reactors, Thorhallsson and Karlsdottir carried out both microstructural and chemica analysis, through a combination of two techniques. The first of these was 'scanning electron microscopy' (SEM), which produced high-resolution images by measuring how focused beams of contained in corrosion products.

The second technique was 'energydispersive $x$-ray spectroscopy' (XEDS). Here, the electrons contained within a sample's atoms are excited to higher energy levels by incident $\mathrm{X}$-rays; then transition back to their ground-state energy levels, emitting an X-ray photo in the process. By measuring the $X$-ray energies at which these emitted photons appeared, the researchers could determine the precise chemica compositions of their AN IMPROVED PERFORMANCE Altogether, the duo's experiment had Wofold aim. In the first part, they aimed

the carbon steel piping materials currently used in geothermal energy generation. the carbon steel was prone to localised damage, forming patches of oxide, sulphide, and chloride corrosion products. In contrast, an oxide corrosion layer formed uniformly across the entire surface the second reactor.

Finally, the third reactor gained two uniform layers of corrosion: featuring sulphide upper layer, and an oxide

gas, the result remained the same. developed titanium that the newly prone to corrosion in any of the testing conditions', describes Thorhallsson.

\section{NEW PROSPECTS FOR}

GEOTHERMAL ENERGY

This outcome clearly showcased the advantages of the new titanium alloy. With the ability to operate over extensive lifetimes without either corroding, or mechanically destabilising under high

The new titanium alloy could be a feasible piping material candidate where extreme corrosive or multiphase conditions of the geothermal fluid is expected.

sublayer. For the first time, the results provided Thorhallsson and Karlsdottir

it ideal for use in real geothermal wells. with a clear picture of how carbon stee conditions of geothermal wells, and ultimately, highlighted the numerous shortcomings of the material.

In the second part of their experiment, the researchers kept the conditions in each of the reactors exactly the same, but replaced their carbon steel piping material with their new titanium alloy Regardless of whether the sample phids existed in a single, superheated
In turn, these advantages could provide ar greater incentives for businesses and local governments in tectonically of geothermal energy. Ultimately, the progress in bring about long-awaited progress in a form of renewable energy which may one day be just as economically competitive as win and solar power - perhaps bringing reliance on fossil fuels. active regions to expand their rollout

\section{Behind the Research

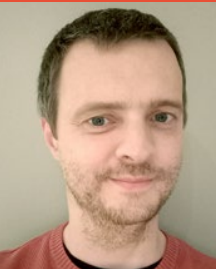 \\ Andri Thorhallsson \\ E: ath196@hi.is E: snk@hi.is W: www.mdpi.com/2624-5558/2/2/11 \\ (6) Dr Sigrun Karlsotottir}

Research Objectives

Andri Thorhallsson and Sigrun Karlsdottir tested a particular tanium alloy to prevent corrosion when harvesting energy from Earth's crust.

\section{Detail}

Address

Asakor 10, 203 Kopavogur, Iceland

Andri Isak Thorhallson has a BSc in chemical engineering from the University of Iceland and an MSc in chemical engineering from Royal Institute of Technology Sweden. He is now studying a PhD in mechanical engineering from the University of Iceland. The author has worked as a process and technical manager in Aluminiun Smelter, engineering consultant and is now working as a production manager for the

Dr Sigrun Nanna Karlsdottir is a Professor in Mechanical Engineering at the University of Iceland. Her research . of materials. Dr Karlsdottir was the leading scint oxidation reaniser of the material testing on-site at IDDP-1, the hottest geothermal well in the world $\left(450^{\circ} \mathrm{C}\right)$.

Funding

The authors would like to thank the Icelandic Research Fund (RANNIS) grants No 163108-051, 163108-052 and 163108053, Geothermal Research Group (GEORG) and Energ/ Research Fund (Landsvirkjun) for funding this project.

\section{Collaborators}

The authors would like to give gratitude to employees at the Innovation Center of Iceland (ICI) and employees at Grein Research for their technical assistance. The authors Would also like to give gratitude to Titanium Metals ation and for providing

NESTit,

UNIVERSITY OF ICELAND

\section{References}

Thorhallsson, Al, Karlsdottir, SN, (2021) Corrosion Behaviour of Titanium Alloy and Carbon Steel in a High-Temperature, Single and Mixed-Phase, Simulated Geothermal Environm

\section{Personal Response}

Do you believe your discoveries could lead to faster development of geothermal energy in Iceland?

II I believe that geothermal energy producers will think more seriously in future about using titanium piping materials where the geothermal fluid is very corrosive
or where multiphase conditions can be expected. In recent years, growing interest has been shown in deep geothermal wells already drilled have shown the extremely corrosive conditions can be expected where the use of more corrosion-resistant material, such as titanium, is necessary to withstand the harsh conditions
of the geothermal fluid.

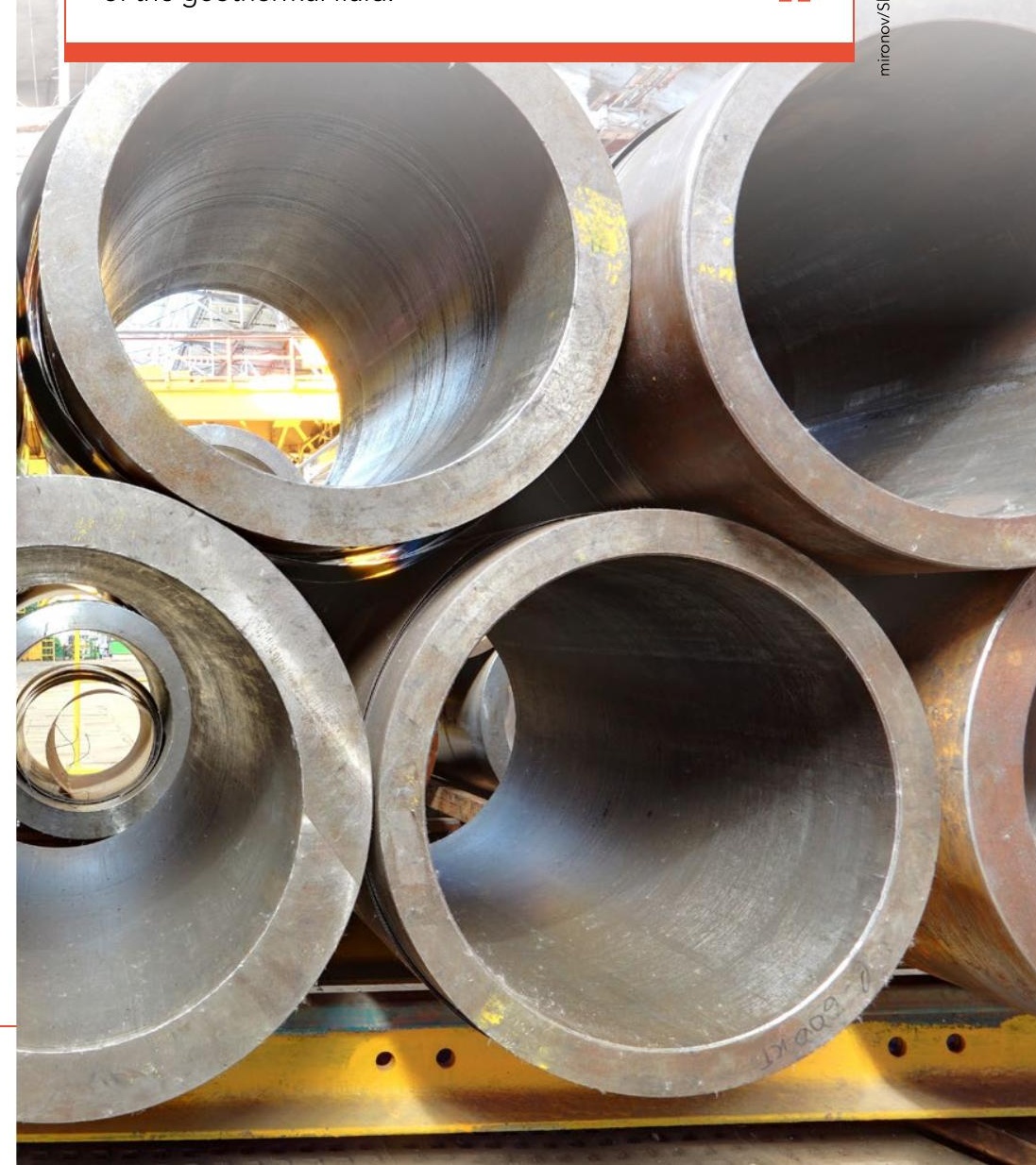

